
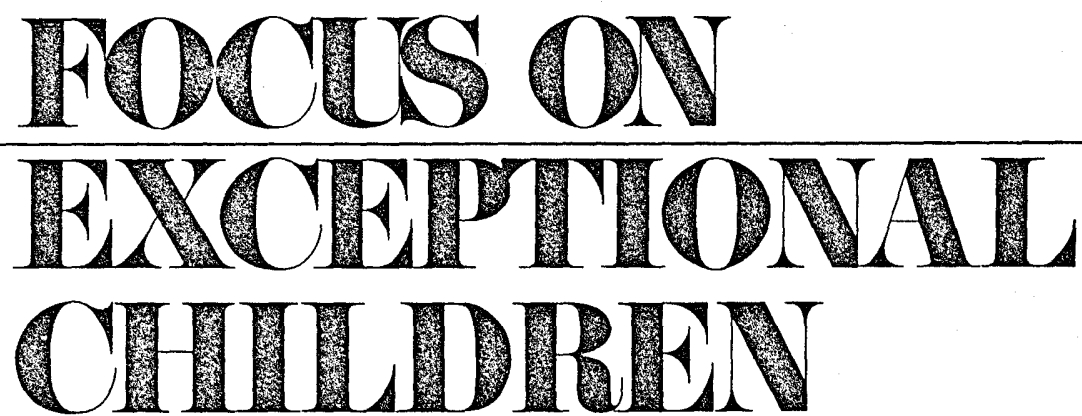

\title{
Learning Disabilities in Adolescent and Young Adult Populations: Research Implications
}

\author{
Donald D. Deshler, Jean B. Schumaker, Gordon R. Alley, \\ Michael M. Warner, and Frances L. Clark
}

The learning disability (LD) field traditionally has devoted most of its attention and resources to the issues of service delivery and teacher training. In recent years, however, research and validation activities have been given increased emphasis. A significant amount of research on LD populations has been conducted by five LD Research Institutes funded by the Office of Special Education and Rehabilitation Services.* One of them, the University of Kansas Institute for Research in Learning Disabilities (KU-IRLD) has had as its research focus the LD adolescent and young adult. Empirical information is greatly lacking on LD adolescents and young adults in particular, and underachieving adolescents in general (Deshler, Warner, Schumaker, \& Alley, in press). Most field practices for these adolescents have been based largely on clinical beliefs and nonvalidated models of assessment and instruction.

As a result of our research during the past four years, we have a clearer, but by no means definite, sense of what the condition of learning disabilities means in adolescent and young adult populations. We hope that program decision making will be enhanced by these data. The findings will be reviewed here, along with their implications, for the LD adolescent as a learner, to describe the demands of the secondary school that LD students face every day, and to discuss interventions that are being developed to help LD adolescents compensate for their deficits and survive the demands of the mainstream curriculum in secondary schools. The four major areas of findings are in academic achievement and ability, cognitive processing, setting demands, and academic interventions.

The authors have all been affiliated with the University of Kansas Institute for Research in Learning Disabilities (KU-IRLD), where Dr. Deshler is Director, Dr. Schumaker is Coordinator for Research. Dr. Alley is a Research Associate (and Professor in the University of Kansas Department of Special Education), Dr. Warner is a Research Scientist, and Dr. Clark is formerly of the Institute, now an Assistant Professor, Department of Special Education, University of Louisville.

*The five institutes, funded under Title VI-G of PL 91-230 from 1977 to 1983, are at Columbia University (Teacher's College), University of Illinois-Chicago Circle, University of Kansas, University of Minnesota, and University of Virginia.

○ Love Publishing Company, 1982 


\section{ACADEMIC ACHIEVEMENT AND ABILITY}

One would have difficulty defending the assumption that sound instructional programs can be developed for any group of students with special learning needs if the nature and extent of their learning problems cannot be described. Yet, to date, the extent of published information pertaining to the academic and cognitive characteristics of adolescents with learning disabilities remains extremely limited. The existing data on adolescents are largely either anecdotal or stem from studies of students referred to psychological, medical, and educational clinics. Consequently, drawing conclusions about public school LD adolescents based on this information is risky at best.

As part of our epidemiological study of LD adolescents, we investigated the achievement and ability levels of these students as compared to those of lowachieving (LA) students. In addition, we were interested in the ways in which school-defined LD adolescents differ from other low-achieving (LA) students with respect to ability and achievement. Each of the LD and LA students included in our epidemiological study was administered subtests comprising the three achievement clusters of the Woodcock-Johnson Psychoeducational Battery (WJPB): Reading, Written Language, and Math. In addition, each of the students was administered the

FOCUS ON EXCEPTIONAL CHILDREN (ISSN 0015-511X) (USPS 203-360) is published monthly except June, July, and August as a service to teachers, special educators, curriculum specialists, administrators, and those concerned with the special education of exceptional children. This journal is abstracted and indexed in Exceptional Child Education Resources, and is also available in microform from Xerox University Microfilms, Ann Arbor, Michigan. Subscription rates, $\$ 15.00$ per year. Copyright 1982, Love Publishing Company. All rights reserved. Reproduction in whole or part without written permission is prohibited. Printed in the United States of America. Second class postage is paid at Denver, Colorado. POSTMASTER: Send address changes to:

\section{Love Publishing Company \\ Executive and Editorial Office 1777 South Bellaire Street \\ Denver, Colorado 80222 \\ Telephone (303) 757-2579}

\section{EDITORIAL BOARD}

Edward L. Meyen

University of Kansas

Richard J. Whelan

University of Kansas Medical Center

Carolyn Acheson

Senior Editor
Stanley F. Love Publisher
Block Design and Vocabulary subtests of either the Wechsler Intelligence Scale for Children - Revised (WISC-R) or the Wechsler Adult Intelligence Scale (WAIS), depending upon their age. Each student's fullscale IQ was estimated from these subtests. Student test performance was studied as it differed across school districts and across the junior- and senior-high levels.

The following related issues were targeted: Are LD adolescents a special subgroup of the much larger group of low-achieving and underachieving adolescents in the secondary schools? Are their deficiencies best described as very general or as specific? Do these students continue to make progress in developing basic academic skills as they move through the secondary grades? Do any measures discriminate LD adolescents from other low achievers? Are learning disabilities defined differently in different districts? Finally, do LD adolescents possess sufficient study skills to profit from participation in the regular classroom?

\section{LD Adolescents are the Lowest of the Low Achievers}

As reported elsewhere (Warner, Alley, Deshler, \& Schumaker, 1980), LD adolescents exhibit low levels of basic skill development compared to their age peers including other low achieving (LA) adolescents. They typically score below the 10th percentile on the three achievement clusters of Reading, Written Language, and Mathematics. Of these three areas, the Written Language cluster of the $W J P B$ was found to be the most powerful single discriminator of the LD and LA samples in our study. A recent analysis of the major types of items from this cluster revealed that a powerful discrimination of LD and LA students can be achieved by using only the items that measure spelling. Thus, with respect to identification of $L D$ adolescents, spelling deserves strong consideration as a discriminating variable.

\section{Most LD Adolescents Exhibit Very General Deficiencies}

LD adolescents generally exhibit low performance in the achievement areas of reading, written language, and math (Warner et al., 1980). For example, of 307 LD students, 200 scored at or below the 10 th percentile of the Written Language cluster of the WJPB. Of these 200, 
$80 \%$ (or 160 ) were equally low in the Reading cluster, and $72 \%$ (or 143) were equally low on the Mathematics cluster.

A study of the IQ data presents more factors to be considered. Based on the Block Design and Vocabulary subtests of the WISC-R/ WAIS, each student's full-scale IQ score was determined. About half the students in each of these groups scored above their respective group means; about half scored below. In a related study, Skrtic (1980a) found that LD adolescents performed significantly lower than their non-LD peers on a measure of formal reasoning ability.

In addition about three-fourths of our total LD sample met proposed federal criteria for severe discrepancy (Federal Register, November 1976); that is, these students were achieving at or below $50 \%$ of the expected grade level in one or more of three achievement areas (Warner, 1981). A substantial portion (40\%) of the lowachieving group also met this criterion.

Thus, a number of LD adolescents exhibit substantial underachievement; i.e., their IQ test performance is much higher than their achievement test performance. On the other hand, a large proportion of LD adolescents scored in the 80s and below on our IQ measure. This low measured intelligence combined with low achievement levels suggest that $L D$ adolescents' disabilities are very general rather than specific.

\section{LD Adolescents Demonstrate Little Growth in Basic Skills Across the Secondary Grades}

Despite the major role of basic skill remediation in most secondary LD programs (Deshler, Lowrey, \& Alley, 1979), our data suggest that during adolescence, growth in these skills is modest among LD students. A plateau seems to be reached by the time students reach tenth grade. Because we did not actually follow individual students as they progressed through the secondary grades, to obtain longitudinal data, inferences based on existing, cross-sectional data remain tentative.

In the areas of reading and written language, $L D$ students' average achievement in seventh grade is at a high third-grade level and plateaus at the fifth-grade level in the senior high grades. In the area of mathematics, average achievement in seventh grade is at the beginning fifth-grade level and plateaus at the sixthgrade level in the senior high grades.

\section{Measures of Academic Ability and Achievement Are the Most Powerful in Discriminating LD Adolescents from Other Low Achievers}

In our epidemiological study, data were collected on a large number of variables in addition to those currently under discussion. These included attitudinal, behavioral, and demographic characteristics as reported by parents, teachers, and the youths themselves. Results indicated that once the LD and low-achieving groups were equated statistically for achievement and ability, virtually none of the other variables served to reliably differentiate the two groups.

Based on this finding, it may be concluded that, aside from being the lowest of the low achievers in their school districts, $L D$ adolescents are more like other low achievers than they are unlike them. This conclusion is supported by two recent comparisons of LD and low-achieving students at the elementary level (Taylor, Satz, \& Friel, 1979; Ysseldyke, Algozzine, Shinn, \& McGue, 1979).

\section{Low Achievement and Underachievement Vary With the District of Attendance}

As part of our epidemiological study, levels of achievement and underachievement were compared in three different school districts. One of the districts was relatively high in terms of the citizens' socioeconomic status (SES), another district was composed of citizens predominantly of lower socioeconomic status, and the third district was at a middle level between the other two in SES. Results of the comparison across districts revealed striking differences between the achievement levels of the LD and LA students across the three districts. For example, to achieve maximum discrimination between LD and low-achieving high school students in the low SES district, the 5th percentile of the Written Language Cluster of the $W J P B$ had to be used. In the highest SES district, this figure shifted to the 15 th percentile based on the national norms published in the manual (Warner et al., 1980).

These district effects imply that: (a) each district serves the lowest of its low achievers, and (b) the same students would not necessarily be considered LD by the two different school districts. Clearly, these findings pose a serious dilemma in the pursuit of a consistent definition of learning disabilities. 


\section{LD Adolescents Are Deficient in Study Skills and Strategies Needed for Regular Secondary Classrooms}

In a study of school-classified LD students, a group of secondary LD teachers estimated that more than $85 \%$ of LD adolescents exhibit problems in several areas, including test-taking skills and study skills (Alley, Deshler, \& Warner, 1979). Similarly, Carlson and Alley (1981) found that LD high school students performed significantly more poorly than a group of high-achieving students in note taking, monitoring writing errors, test taking, scanning a textbook passage, and listening comprehension. Also, the performance of the LD students on a set of minimal competency standards for each of the five areas indicated that only $10 \%$ of the LD students met or exceeded minimal competency on three or more of the tests; $22 \%$ of the LD students met or exceeded minimal competency on none of the tests.

Another group of researchers (Schumaker, SheldonWildgen, \& Sherman, 1980) observed LD and non-LD junior high students in their regular classrooms and found that $L D$ students listened much less attentively to statements by the teacher and used a study strategy that researchers called "alternate reading and writing" less often than the non-LD students. Overall, the LD students engaged in $7 \%$ fewer intervals of study behaviors and $16 \%$ more intervals of rule-violating behaviors when compared to the non-LD students.

\section{Educational Implications}

The following educational recommendations are based on a description of students who are actually being served in LD programs. Students who evidenced other handicaps (e.g., sensory impairment or emotional disturbance) were removed from our LD sample. Nevertheless, a restrictive definition of $\mathrm{LD}$ was not applied. Keeping this in mind, a generalization that can be made is that the group actually being served is quite heterogeneous (this group probably could be more correctly viewed as having several subgroups, each with a different predominant educational need). Based on the diversity of the group, three issues arise.

First, to what extent are teaching methods and curricula needed that are unique to $L D$ adolescents, as distinct from low achievers in general? Our data would suggest, or at least fail to contradict, the proposition that similar interventions would be appropriate for both school-defined LD students and low-achieving students.

Second, to what extent should basic skill remediation be emphasized in the curriculum? Assuming that the LD students in our sample have been exposed to this type of remediation for a number of years, the plateauing effect that we found does not support a continual emphasis on remediation, at least in its present form. Rather, a different approach can be taken. As our data show, a substantial proportion of LD adolescents are at or above the fourth-grade level in basic skill development but lack adequate study skills. We believe these students can be supported in the regular curriculum by teaching them specific learning strategies. A more thorough discussion of the rationale and efficacy of the learning strategies approach appears in Deshler et al. (in press). Students whose basic skills are so low that a learning strategies approach is ineffective could benefit from two possible courses of action: (a) the skill deficit may in some instances be bypassed using procedures such as tape recording written material, and (b) a program of basic skill remediation may be initiated, but in a more intensive fashion than is typical.

This leads to the third general issue that arises from our findings. How broad and intensive should an LD program for LD adolescents be? A large number of students in LD programs appear to have significant deficiencies in all the following areas: general academic ability, reading, writing, mathematics, and study skills. In combination, these cognitive and academic deficiencies result in very general performance deficits in secondary schools. A resource room model, in which this LD adolescent receives special help for only one class period per day, is not likely to be sufficiently powerful to address the learning needs of that adolescent. Some LD adolescents may need intensive intervention for a limited time. Students whose deficiencies are less severe and more narrow in scope may benefit from a learning strategies program within a resource room format.

\section{COGNITIVE PROCESSING}

In spite of various controversies, theories of cognitive processing continue to influence thinking and practice in the field of learning disabilities. Process training, as advocated and developed through the 1960s (e.g., Barsch, 1967; Kephart, 1971; Kirk \& Kirk, 1971), came under heavy attack during the early 1970 s as being ineffective 
(e.g., Hallahan \& Cruickshank, 1973; Hammill \& Wiederholt, 1973; Hammill \& Larsen, 1974). During the 1970s and up to the present, however, theories of information processing from developmental and cognitive psychology continue to provide a powerful impetus for research related to learning disabilities. These more recent efforts are based to a greater extent on empirical findings from the study of normal adults and children (Hallahan \& Bryan, 1981). The study of the relationship between information processing and learning disabilities holds promise in that it may lead the way to identification of instructionally meaningful subgroups of LD students, as well as provide direction to the content of instruction.

In much of the LD information processing research, students are presented with tasks that nominally tap processes such as memory or attention. The focus of interest, however, has not been so much on whether or not the students did well, but, rather, on how they approached the task. Based on this kind of studies, LD students have often been documented to approach tasks passively (e.g., Hallahan \& Bryan, 1981; Torgesen, 1977). For example, they are less likely than their normallyachieving peers to use spontaneously specific cognitive operations such as vérbal rehearsal, mental elaborations, and meaningful grouping of stimuli, when asked to memorize material for later recall. These findings have led to two major hypotheses about the causes of such passivity.

As part of the first hypothesis, LD students are seen as deficient or developmentally delayed in executive functioning. Atkinson and Shiffrin (1968) postulated, and Butterfield and Belmont (1977) further conceptualized that the executive is the part of the information processing system that selects and coordinates the use of specific processes, such as rehearsal, in light of the demands of a specific task. Executive skills are higher order skills that include the following metacognitive processes: initial monitoring of a problem or task to see if the goal is clear, other forms of monitoring and checking, making plans, and evaluating the success of implementations of those plans (Brown, 1978).

As part of the second hypothesis, LD students are seen as less active in invoking activities such as rehearsal because they are less intrinsically motivated to perform well or to expend effort on the various tasks, both in and out of school (e.g., Henker, Whalen, \& Hinshaw, 1980; Wong, 1980). This hypothesis is clearly related to the first since one cannot expect an individual's executive and other resources to be martialled without motivation to reach a particular goal.

\section{Many LD Adolescents Exhibit Immature Executive Functioning}

In a comparison of the executive functioning of groups of LD, low-achieving, and normally-achieving adolescents in grades 7 through 12 , students were required to listen to lists of seven words each (Warner, Schumaker, Alley, \& Deshler, 1982). Subjects were asked to repeat the words in an order different from the order in which they were presented. The students were presented with 14 lists. The speed with which the lists were presented was controlled by having students tap a pencil on the table each time they wanted a new word to be presented. By recording the pencil taps and by measuring the length of time between each tap, the students' rehearsal strategies could be inferred independently of accuracy of recall. The measure of executive functioning entailed the degree to which the pattern of pencil tap intervals corresponded to an optimal pattern based on a theoretical and empirical viewpoint.

Results showed that the normally-achieving students were superior to the other two groups (LD and low achievers) both in accuracy and in executive functioning. With one exception, the groups of LD and low-achieving students did not differ from each another along these two dimensions, once the two groups were equated statistically for levels of achievement. The exception consisted of the higher performance of low-achieving females compared to LD females in terms of accuracy, even when the groups were equated with respect to achievement.

In spite of the deficient performance of the LD group as a whole, the findings were that, depending on grade level and district of attendance, between $40 \%$ and $48 \%$ of the LD sample adopted an optimal strategy on this relatively novel task. In conclusion, our data support the idea that, as a group, LD adolescents exhibit deficiencies in executive functioning. Rather than being unique to the condition of learning disabilities, however, these deficiencies appear to characterize low achievers in general. Equally important was the finding that not all LD students failed to adopt an optimum strategy. These results, when combined with the fact that a proportion of LD adolescents have IQ scores above the normative mean of 100 , indicate that, at least for a significant 
proportion, executive processing is among the strengths, rather than the deficits, of $L D$ adolescents.

\section{Cognitive Deficiencies Negatively Influence Performance Despite Increased Incentives to Do Well}

A study by Mellard and Alley (1982) explored the relationship between motivation and strategy use by comparing LD students' performance on a task in a situation in which no incentives were used to a situation in which monetary incentives were used. In previous work with elementary-aged students (e.g., Hallahan, Tarver, Kauffman, \& Graybeal, 1978; Haines \& Torgesen, 1979), it has been found that LD students' performance on tasks requiring rehearsal can be improved simply by providing monetary incentives. But in Mellard and Alley's complex discrimination learning task, in which students were required to keep track of the status of each of eight bivalued visual stimuli, the performance of LD adolescents was not improved by the payment of cash for good performance.

Mellard and Alley concluded that the LD students were inefficient in their approach to the task and that this inefficiency was not altered by incentives and verbal feedback on the correctness of their responding. Compared to a group of normal controls, the LD students, as a group, were less likely to profit from experimenterprovided feedback, and they were less likely to follow a logical, strategic, problem-solving approach. Although these behaviors are similar to those usually characterized as "passive" (Torgesen, 1977), Mellard and Alley noted that the LD students in their sample seemed to be actively engaged in the task. Thus, remediation of cognitive deficiencies in LD adolescents is not as simple as altering motivational factors in the adolescents' environments; the cognitive deficiencies themselves must be addressed.

\section{Educational Implications}

Available data pertaining to the executive and motivational characteristics of $L D$ adolescents are still so limited that only tentative implications can be drawn. Based on the findings of Brown (1978) and Butterfield and Belmont (1977) with respect to mentally retarded youngsters, training executive skills in LD adolescents who exhibit executive functioning deficits may be most worthwhile. Given the data at hand, some LD students may learn to use their already developed skills rapidly. For others, however, training these skills may be a long process.

Much more research is needed on the impact of motivation on LD adolescents' cognitive performance. Nevertheless, the manipulation of motivation, by itself, will not likely sufficiently improve the performance of LD adolescents, especially on complex tasks. Rather, interventions also will have to be aimed at improving cognitive efficiency. Teaching cognitive strategies to LD adolescents should result in improved efficiency.

\section{SETTING DEMANDS}

A major issue in the field of learning disabilities is the relationship between the setting in which the individual must function and the disability. Traditionally, the conceptualization of learning disabilities has centered solely on the individual's attributes and, thus, has focused on causes of the disability within the individual. Following this conceptualization, educators planning interventions for LD adolescents have assumed that the skills taught to elementary LD students are also essential for secondary LD students (if these have not been mastered previously). As interest in the condition of learning disabilities in adolescence has increased, however, differences in the settings in which adolescents must function have been recognized. Despite this recognition, little research specifying the nature of these differences has been available.

In designing the KU-IRLD research program, Lewin's (1935) formulation of behavior was adopted as an appropriate means of conceptualizing and researching learning disabilities. Thus, learning disability was viewed as a condition resulting from a complex interaction between the learner and the environment. Several KU-IRLD studies have provided information about the settings in which adolescents must perform and have contributed to a greater understanding of the interaction between the LD individual and the environment.

\section{Secondary School Settings Place Complex Demands on Certain Skills}

In a study of secondary school settings (Moran, 1980), the oral language of 25 senior high and 7 junior high school teachers was audiotaped for an entire class session (45 to 50 minutes). Analysis of these tapes provided a perspective of the secondary school classroom environment. 
First, secondary teachers were found to lecture significantly more often than they involved students in discussion through questioning. Surprisingly, junior high teachers lectured as much as senior high teachers. Second, teachers presented few advance organizers that might help students listen more efficiently. Third, checks for understanding of directions and feedback about student performance were few in secondary classrooms. Fourth, teachers' self-reported language behavior differed from the observed data. Although teachers perceived their use of "Wh" questions about content as their most frequent behavior, observation revealed that they more frequently stated facts or opinions or gave commands. Fifth, teachers spoke four times for each student utterance. Sixth, the mean number of morphemes per teacher utterance was 10 , exceeding even the recommended number for adult processing of information.

Moran concluded that the teaching style in core courses at the secondary level places heavy demands on LD students' listening skills. Also, because the students are not asked to demonstrate knowledge verbally, it places heavy demands on their writing skills as well.

Schumaker et al. (1980) observed LD and non-LD junior-high students and their teachers in regular classrooms. They found that seatwork was the class format most often used ( $47 \%$ of the time). In this format students were required to work independently on assignments using reading and writing skills. The next most frequently used class format was lecture $(21 \%$ of the time), followed by class discussion ( $10 \%$ of the time), and audiovisual aids (10\% of the time). Less frequently used formats were group work, individual reports to the class, and free time.

These results replicate Moran's study because the most commonly used format involving listening or speaking was the lecture format. Schumaker et al. also reported little student-teacher interaction. Students rarely requested help from or answered questions for teachers. During lectures, students rarely asked questions or made comments. Teachers rarely asked questions, made suggestions to individual students, or gave verbal feedback to the students about their work.

In an observational study of the interactions of regular classroom teachers and LD and non-LD students in grades 9-12, Skrtic (1980b) found that regular classroom teachers interacted with LD students as often as they interacted with non-LD students. The content of these interactions was predominantly verbal and more often related to academic tasks than to social interactions.
Teachers directed the same proportion of positive and negative academic interactions to LD and non-LD students, but more negative social interactions were directed toward the non-LD students. In addition, teachers offered assistance to LD students as often as they offered to help non-LD students. In class, LD students initiated interactions with the teacher by volunteering answers and requesting help as often as non-LD students. Based on these results, the data show that LD students: (a) must interact verbally in both academic and social situations with the teacher, (b) must respond to the teacher's offer of assistance, and (c) must (and do) initiate interaction in the classroom (e.g., volunteering answers, requesting help).

Knowlton and Schlick (in preparation) validated the expectations of mainstreamed LD students held by 27 secondary regular classroom teachers. The data show that teachers hold expectations of LD students in five categories, four of which are pertinent to the present discussion by reflecting setting demands): skills to cope with subject matter (such as reading and spelling); general study skills (e.g., note taking, composition and writing, use of the library and references); independent work habits (e.g., locating correct page, requesting assistance when needed, making appropriate response to classroom work situation); and communication skills (e.g., speaking clearly, seeking information).

Schools are not the only settings in which LD adolescents are expected to demonstrate oral language, reading, writing, and listening skills. Mathews, Whang, and Fawcett (1980) identified and validated 13 employment-related skills for an occupational skills assessment instrument. Both social and nonsocial interaction skills were regarded as highly important for obtaining and maintaining employment. The skills require: (a) reading and writing (writing a letter to request an interview in response to a help-wanted advertisement, completing a federal income tax form), (b) listening (accepting both suggestions and criticism from an employer, and (c) oral language (telephoning to request an interview, participating in an interview, providing constructive criticism to co-workers, explaining a problem to a supervisor, complimenting a co-worker).

Data show that regular classroom teachers at the secondary level not only expect LD adolescents' reading, writing, oral language, and listening skills to be already developed, but they also place demands on those skills during classroom instruction. In addition, demands are placed on these skills in out-of-school settings. Thus, 
successful performance by $L D$ adolescents mainstreamed in the secondary school setting and employed in work settings requires that they meet language demands placed on them in those environments.

\section{Settings in Which LD Adolescents Must Function Require the Ability to Function Independently}

Data provided by Moran and by Schumaker et al. have shown that teachers give little feedback (positive or negative) to students in secondary classrooms. In addition, Moran found that teachers provide few advance organizers for students and only infrequently check for students' understanding of instructions. Skrtic found that LD students must volunteer answers and must request help. Schumaker et al. found that secondary students were required to work independently during $47 \%$ of class time. Knowlton and Schlick's study of secondary regular classroom teachers' expectations of LD students indicated that independent work habits constitute a major category of expectations (e.g., locates correct page, budgets time, requests assistance when needed, makes appropriate response to classroom work situations, and works beyond expectations). This category consisted of the largest number of individual expectations among the five categories in their study.

Although the study by Mathews et al. of employmentrelated skills did not directly address independent functioning, performance of several of the specific skills on their test (e.g., getting a job lead from a friend, writing a letter to request an interview in response to a helpwanted advertisement, telephoning to request an interview when a job is not open, complimenting a co-worker on a job done well) requires the individual to take the initiative and function independently.

Together, these data provide a picture of the environments in which the LD adolescent is expected to perform independently without continuous monitoring. Further, in school settings $L D$ students are required to recognize their need for assistance and to assume the initiative in obtaining that assistance. In employment settings $L D$ adolescents are expected to assume the initiative in completing job-related tasks considered important by employers and by employed adults.

\section{Educational Implications}

These findings indicate the importance for LD adolescents of the consideration of setting demands and conditions when making educational decisions. As a whole, the data suggest that the demands older LD individuals encounter are markedly different from those younger LD children face, especially in school settings. To be successful in secondary school settings, LD adolescents must possess a broad array of strategies that will allow them to deal independently and effectively with existing information processing demands. Since teacher instruction is largely unidirectional and presented in a lecture format, students must possess sophisticated listening, note-taking, attending, and problem-solving skills.

Although learner characteristics are critical to development of educational programs, conditions and demands of the environment and interactions between learner characteristics and the environment are also critical factors and should not be overlooked. In essence, intervention procedures should be designed to increase LD adolescents' learning efficiency and effectiveness so these individuals can cope more adequately with the demands of the settings in which they must function.

\section{ACADEMIC INTERVENTIONS}

Since the mid-1970s the learning disability field has directed significant attention toward methodologies for intervening successfully with LD adolescent populations (Alley \& Deshler, 1979). Intervention approaches focusing on the learner have ranged from basic skill remediation procedures (Goodman \& Mann, 1976) to alternative curriculum models (Wiederholt \& McEntire, 1980). In addition, some approaches have advocated changing the setting and conditions for learning rather than changing the learner (Hartwell, Wiseman, \& VanReusen, 1979; Mosby, 1979).

Given the findings of our epidemiology research on learner characteristics and setting attributes, the intervention approach studied by the KU-IRLD has been a learning strategies approach. Learning strategies, as defined by Alley and Deshler (1979), are "techniques, principles, or rules that will facilitate the acquisition, manipulation, storage, and retrieval of information across situations and settings" (p. 13). A learning strategies approach is designed to teach students how to learn rather than teaching them specific content. This intervention approach was adopted as the focus of the $\mathrm{KU}$ IRLD research for the following reasons: (a) the demands of the secondary curricula require the acquisition of skills (such as problem solving, error monitoring, scanning, and the like) that will enhance the student's ability 
to cope with the heavy content requirements, and (b) instruction of basic academic skills in areas such as word attack and mathematical computation, while important, is not sufficient to allow the LD individual to successfully adjust in school or the world of work.

Our intervention research has been a multistage effort, with each stage designed to answer a key question. The first question was one of internal validity: Can a specific learning strategy intervention package be demonstrated to cause a change in LD students' performance? A second key question related to the degree to which learning strategy packets as designed by the KU-IRLD could be successfully accommodated into existing secondary resource rooms. Finally, we asked questions related to the external validity of the learning strategy packets: What proportion of the LD population responds to the learning strategy approach? What subpopulations respond differently?

\section{Tentative Research Conclusions}

\section{Learning Strategy Interventions Cause Change in LD Adolescents' Performance}

To demonstrate that learning strategy interventions cause a change in LD students, a series of single-subject experimental design studies was conducted. Each study tested a specific learning strategy. The strategies studied were designed to help students deal with three major demands of the secondary school: gaining information from written materials, expressing information in writing, and gaining information from oral material. Studies have been completed on the following strategies: word identification, paraphrasing, visual imagery, self-questioning, multipass (a strategy for attacking textbook chapters), sentence writing, paragraph organization, error monitoring, and listening and note taking. Each strategy was taught to students with a specific teaching methodology consisting of nine steps: make the student aware of his/ her current learning habit; describe the new learning strategy; model the strategy; have the student verbally rehearse the strategy; have the student practice the strategy in controlled materials; give feedback; have the student practice the strategy in grade-level materials; give feedback; and test (Deshler, Alley, Warner, \& Schumaker, 1981).

Students selected for this research were formally classified as learning disabled and were enrolled in special education programs in their public high schools. Stu- dents were taught a particular strategy individually by a certified LD teacher. Each strategy was designed so that student change after learning the strategy would be observable and objectifiable. With the reading strategies, for example, the students were observed, with intermittent probes to determine whether the students was using the strategy. When the student had finished reading, either verbal reports of information learned were collected or the student was given a written test covering the information.

Thus far, results are encouraging. Of the 70 students who have received individual strategy instruction, only one has been unable to learn a strategy. Another student has demonstrated mastery of two reading strategies in controlled materials but was unable to perform them in grade-level materials. In addition, although two students showed marked gains in their note-taking skills, they did not reach criterion on the note-taking strategy within the time allowed. All remaining students have learned their strategy to criterion and, in the case of reading strategies, have been able to generalize their use of strategy skills to grade-level materials. In short, gains from baseline performance levels to after-intervention levels are clear.

Given these results and the large number of replications conducted, the learning strategy packages developed by the KU-IRLD do produce changes in most LD adolescents' performance. Furthermore, these students are able to generalize their use of the strategies to gradelevel materials - which is critical if the students' performance in the regular classroom is to improve.

\section{Learning Strategy Packets Can Be Used \\ Within Existing Secondary School \\ Resource Room Programs}

The questions of how practical the learning strategy packets were for application in a resource room setting became paramount after establishing their internal validity. Teacher feedback on the strategy packets indicated that, while they were pleased with the results, they would not be able to routinely use the packets in their resource rooms because of the heavy requirements for individual instruction.

As a result of this feedback, modifications were made. First, specific guidelines were written for teachers to follow when teaching the strategies to groups of students (e.g., four to six students). For each of the nine instructional steps, specific suggestions were given on how to teach the strategy to a group. Second, each of the in- 
structional packages was revised to reflect the requirements of group instruction. Finally, a brief instructional module was designed to familiarize students with group work. This module included rules to follow in group work, a discussion of the importance of cooperative learning efforts, and similar things.

The performance of high school students who have been instructed in strategies through a group format compares favorably with the performance of those taught individually. Also, teachers have indicated high satisfaction with the procedures, as have the students. In fact, students in the group program were more satisfied than students in another program involving less studentteacher interaction.

\section{Success in Learning Strategy Intervention Is a Function of Student Attributes}

As might be expected, strategies instruction has not been found to be appropriate for all secondary LD students. Thus far, the prerequisites specified by the instructional packages designed by the KU-IRLD screen out certain students - for example, those who read below the fourth-grade level. For the students who have received strategies instruction, however, some interesting observations can be made.

Teachers who have participated in field testing the packets seem repeatedly to divide the participating LD students into two groups. One is characterized by the quickness with which they learn and independently apply the strategy ("It's as if he (she) just wasn't aware of the strategy for a given task, but once taught, it is readily applied"). The second group has been characterized by the slow, plodding manner in which students approach strategies instruction and reach mastery. Nevertheless, they do reach mastery given enough time. These observations have led the KU-IRLD into a line of research designed to investigate specific student characteristics associated with the two types of strategies learning. For example, completed studies (e.g., Mehring, 1981; Wolf, 1982) have correlated learning strategy acquisition with factors such as locus of control, knowledge of word meaning, field dependence, and learning potential. Analysis of the results of these studies has not demonstrated an association between these factors and strategies acquisition. Additional variables such as IQ and achievement test scores are currently under investigation. A clearer understanding of student attributes related to strategy acquisition will have direct implications for instructional decision making.

\section{Educational Implications}

The results of our academic intervention research on learning strategies portray a somewhat optimistic picture for the older LD individual's ability to master skills directly related to the demands of secondary school settings. The favorable results are particularly encouraging in light of our epidemiological data indicating that LD adolescents plateau in basic skill development between the fifth and seventh grade levels. According to our intervention research, $L D$ adolescents can be taught specific strategies that they subsequently can apply to various materials, even those used in their regular classrooms.

Successful application of these packets in secondary school resource room settings is encouraging in view of the heavy student caseloads most LD teachers carry. Although some progress has been made, many intervention questions remain. Among the most pressing are: In what sequence can the strategies be most effectively taught? What student attributes are correlated with effective strategy learning? How much can younger LD students (junior high and elementary school students) benefit from strategy instruction? What is the role of other intervention procedures (e.g., curriculum modification, basic skill remediation) in an overall intervention program for LD adolescents? These questions will receive attention of the KU-IRLD in subsequent months.

\section{CONCLUSIONS}

The failure of individuals to function adequately in their environments is of great concern to the individuals themselves, to educators (both regular and special), and to parents. The data bout LD adolescents and young adults presented here, and in a companion article to follow in a later issue of Focus on Exceptional Children, reveal a complicated picture of both the characteristics of $L D$ individuals and the characteristics and demands of their environments. As these characteristics are identified, the challenge is then to understand the complex interaction between the individual characteristics and the setting demands.

Even now, however, a tentative statement about the interaction between individual characteristics and setting demands can be made. Settings in which LD adolescents and young adults are expected to function place heavy demands on their cognitive and academic skills, the very areas in which deficit performances by LD adolescents have been identified. Thus, when placed in a setting that 
necessitates performances of skills in which they are deficient, LD adolescents not surprisingly perform more poorly than their peers. In spite of this, LD adolescents are not markedly different from others who are having difficulties in the same environments. As noted previously, $\mathrm{LD}$ adolescents in school environments are similar to low achievers in this setting.

Based on what we know now, interventions that teach the LD individual how to learn, that help the LD individual recognize opportunities for generalizations, and that specifically teach the student how to generalize appear to be the most promising, based on characteristics of the adolescent LD population. The intervention research shows that we can teach the strategies and that some generalization does occur.

Our knowledge of the contribution of individual characteristics, setting demands, and the interaction of characteristics and demands and learning strategies interventions is growing. Greater awareness of the contribution of these to the complexity of learning disabilities and their remediation will enable us to refine the interventions to significantly impact learning disabilities in adolescents and young adults.

\section{REFERENCES}

Alley, G. R., \& Deshler, D. D. Teaching the learning disabled adolescent: Strategies and methods. Denver: Love Publishing Co., 1979.

Alley, G. R., Deshler, D. D., \& Warner, M. M. Identification of learning disabled adolescents: A Bayesian approach. Learning Disability Quarterly, 1979, 2(2), 76-83.

Atkinson, R. C., \& Shiffrin, R. M. Human memory: A proposed system and its control processes. In K. Spence \& J. Spence (Eds.), The psychology of learning and motivation (Vol. 2). New York: Academic Press, 1968.

Barsch, R. H. Achieving perceptual-motor efficiency: A spaceoriented approach to learning. Seattle, WA: Special Child Publications, 1967.

Brown, A. L. Knowing when, where and how to remember: A problem of metacognition. In R. Glaser (Ed.), Advances in instructional psychology. Hillsdale, NJ: Erlbaum, 1978.

Butterfield, E. C., \& Belmont, J. M. Assessing and improving the executive cognitive function of mentally retarded people. In I. Bailer \& M. Sternlicht (Eds.), The psychology of mental retardation. New York: Psychological Dimensions, 1977.

Carlson, S. A., \& Alley, G. R. Performance and competence of learning disabled and high-achieving high school students on essential cognitive skills (Research Report No. 53). Lawrence, KS: University of Kansas Institute for Research in Learning Disabilities, 1981 .

Deshler, D. D., Alley, G. R., Warner, M. M., \& Schumaker, J. B. Instructional practices for promoting skill acquisition and generalization in severely learning disabled adolescents. Learning Disability Quarterly, 1981, 4(4), 415-421.

Deshler, D. D., Lowrey, N., \& Alley, G. R. Programming alternatives for learning disabled adolescents: A nationwide study. Academic Therapy, 1979, 14, 54-63.

Deshler, D. D., Warner, M. M., Schumaker, J. B., \& Alley, G. R. The learning strategies intervention model: Key components and current status. In J. D. McKinney \& L. Feagams (Eds.), Current topics in learning disabilities. New York: Ahlex Publishing Corp., in press.

Federal Register. Washington, DC: Department of Health, Education and Welfare, Nov. 1976.

Goodman, L., \& Mann, L. Learning disabilities in the secondary school. New York: Grune \& Stratton, 1976.

Haines, D. J., \& Torgesen, J. K. The effects of incentives on rehearsal and short-term memory in children with reading problems. Learning Disability Quarterly, 1979, 2(2), 48-55.

Hallahan, D. P., \& Bryan, T. H. Learning disabilities. In J. M. Kauffman \& D. P. Hallahan (Eds.), Handbook of special education. Englewood Cliffs, NJ: Prentice-Hall, 1981.

Hallahan, D. P., \& Cruickshank, W. M. Psycho-educational foundations of learning disabilities. Englewood Cliffs, NJ: Prentice-Hall, 1973.

Hallahan, D. P., Tarver, S. G., Kauffman, J. M., \& Graybeal, N. L. A comparison of the effects of reinforcement and response cost on the selective attention of learning disabled children. Journal of Learning Disabilities, 1978, 11, 430-438.

Hammill, D. D., \& Larsen, S. C. The effectiveness of psycholinguistic training. Exceptional Children, 1974, 41, 5-15.

Hammill, D. D., \& Wiederholt, J. L. Review of the Frostig Visual Perception Test and the related training program. In L. Mann \& D. Sabatino (Eds.), The first review of special education (Vol. 1). New York: Grune \& Stratton, 1973.

Hartwell, L. K., Wiseman, D. E., \& VanReusen, A. Modifying course content for mildly handicapped students at the secondary level. Teaching Exceptional Children, 1979, 12(1), 28-32.

Henker, B., Whalen, C. K., \& Hinshaw, S. P. The attributional contexts of cognitive intervention strategies. Exceptional Education Quarterly, 1980, 1, 17-30.

Kephart, N. C. The slow learner in the classroom (2nd ed.). Columbus, OH: Charles E. Merrill, 1971.

Kirk, S. A., \& Kirk, W. Psycholinguistic learning disabilities: Diagnosis and remediation. Urbana, IL: University of Illinois Press, 1971.

Knowlton, H. E., \& Schlick, L. Secondary regular classroom teachers' expectations of learning disabled students (Research Report in preparation). Lawrence, KS: University of Kansas Institute for Research in Learning Disabilities, in preparation.

Lewin, K. A dynamic theory of personality: Selected papers (D. K. Adams \& K. E. Zender, trans.). New York: McGraw-Hill, 1935.

Mathews, R. M., Whang, P. L., \& Fawcett, S. B. Behavioral assessment of occupational skills of learning disabled adolescents (Research Report No. 6). Lawrence, KS: University of Kansas Institute for Research in Learning Disabilities, 1980.

Mehring, $\mathrm{T}$. The interaction of selected aptitude and cognitive style measures with a learning strategies intervention to teach selfquestioning to junior high school learning disabled students. Unpublished doctoral dissertation, University of Kansas, 1981.

Mellard, D. F., \& Alley, G. R. Production deficiency vs. processing dysfunction: An experimental assessment of $L D$ adolescents (Research Report No. 40). Lawrence, KS: University of Kansas Institute for Research in Learning Disabilities, 1981.

Moran, M. R. An investigation of the demands on oral language skills of learning disabled students in secondary classrooms (Research Report No. 1). Lawrence, KS: University of Kansas Institute for Research in Learning Disabilities, 1980.

Mosby, R. J. A bypass program of supportive instruction for secondary students with learning disabilities. Journal of Learning Disabilities, 1979, 12, 187-190. 
Schumaker, J. B., Sheldon-Wildgen, J., \& Sherman, J. A. An observational study of the academic and social skills of learning disabled adolescents in the regular classroom (Research Report No. 22). Lawrence, KS: University of Kansas Institute for Research in Learning Disabilities, 1980.

Skrtic, T. M. Formal reasoning abilities of learning disabled adolescents: Implications for mathematics instruction (Research Report No. 7). Lawrence, KS: University of Kansas Institute for Research in Learning Disabilities, 1980. (a)

Skrtic, T. M. The regular classroom interactions of learning disabled adolescents and their teachers (Research Report No. 8). Lawrence, KS: University of Kansas Institute for Research in Learning Disabilities, 1980. (b)

Taylor, H., Satz, P., \& Friel, J. Developmental dyslexia in relation to other childhood reading disorders: Significance and clinical utility. Reading Research Quarterly, 1979, 15(1), 84-101.

Torgesen, J. K. The role of non-specific factors in the task performance of learning disabled children: A theoretical assessment. Journal of Learning Disabilities, 1977, 10, 27-34.

Warner, M. M. A comparison of five discrepancy criteria for determining learning disabilities in secondary school populations (Research Report No. 50). Lawrence, KS: University of Kansas Institute for Research in Learning Disabilities, 1981.

Warner, M. M., Alley, G. R., Deshler, D. D., \& Schumaker, J. B. An epidemiology study of learning disabled adolescents in secondary schools: Classification and discrimination of learning disabled and low-achieving adolescents (Research Report No. 20). Lawrence, KS: University of Kansas Institute for Research in Learning Disabilities, 1980.

Warner, M. M., Schumaker, J. B., Alley, G. R., \& Deshler, D. D. An epidemiological study of learning disabled adolescents in secondary schools: Performance on a serial recall task and the role of executive function (Research Report No. 55). Lawrence, KS: University of Kansas Institute for Research in Learning Disabilities, 1982.

Wiederholt, J. L., \& McEntire, B. Educational options for handicapped adolescents. Exceptional Education Quarterly, 1980, l(2), $1-11$.

Wolf, R. Learning potential and its ability to predict student performance on a math problem-solving strategy. Unpublished doctoral dissertation, University of Kansas, 1982.

Wong, B. Motivation for learning in mildly handicapped adolescents and young adults: A review of related theories. Exceptional Education Quarterly, 1980, 1(2), 37-45.

Ysseldyke, J. E., Algozzine, B., Shinn, M., \& McGue, M. Similarities and differences between underachievers and students labeled learning disabled: Identical twins with different mothers (Research Report No. 13). Minneapolis: University of Minnesota Institute for Research in Learning Disabilities, 1979.

Preparation of this manuscript was supported by Contract \#300-77-0494 with the Office of Special Education and Rehabilitation, U.S. Office of Education, through Title VI-G of Public Law 91-230.

The authors of this manuscript wish to acknowledge the instrumental role of Dr. Edward L. Meyen and Dr. Richard Schiefelbusch in the KU-IRLD. Their leadership and direction during the early years of the institute were instrumental in setting a pattern for our overall efforts. Information on obtaining research reports from the KU-IRLD can be obtained by writing to Donald $D$.
Deshler, University of Kansas Institute for Research in Learning Disabilities, 313 Carruth-O'Leary Hall, Lawrence, KS 66045.

\section{ALERT}

New - Virtual Image Analyzer

to Help Identify Dyslexia

As a screening and diagnostic aid for detection of dyslexia and other neural integration problems, Energy Optics is introducing a new product, the Virtual Image Analyzer. Conceived by an audiologist specializing in central hearing disorders, Dr. Leslie Dalton, the device tests the ability of preschool as well as older persons to process complex multisensory symbolic information.

The Virtual Image Analyzer requires the subject to wear earphones and point to the source of an auditory image as it moves back and forth in an arc about the head. The technique is free of socioeconomic, language, or educational achievement biases and limitations. For more complete information, contact: Sonido Division, Energy Optics, Inc., 224 N. Campo St., Las Cruces, NM 88001 .

\section{New - Real Time Graphic Display, Video Captioning for the Deaf}

A still-developing system of video captioning being tested at the National Technical Institute for the Deaf (NTID) is allowing deaf students to read their instructors' words within four seconds from the time they are spoken. Known as Real Time Graphic Display, the system uses a computer, with the aid of a trained stenographer, to translate speech into printed English words displayed on a television screen.

Symbols, which represent sounds rather than actual words, are transmitted electronically to the computer. (Despite the great advances in computer technology, computers are still unable to recognize everyday human speech - hence, the stenographer). The entire spoken record of the class is stored in the computer's memory, allowing a printed transcript to be available to students. For more information on this system, which is still being field-tested and continually refined, contact: NTID, One Lomb Memorial Dr., P.O. Box 9887, Rochester, NY 14623. 